\title{
Study on Agricultural Park Planning Methods Based on Omni-Directional Information Processing Technology*
}

\author{
Xueyuan $\mathrm{Chen}^{1, * *}$, Yongchang $\mathrm{Wu}^{1,{ }^{* * *}}$, and Bingwen $\mathrm{Zhao}^{2}$ \\ ${ }^{1}$ Institute of Agricultural Resources and Regional Planning, \\ Chinese Academy of Agricultural Sciences, Beijing 100081, P.R. China \\ chenxueyuan666@sohu.com, \\ wuyc@mail.caas.net.cn \\ ${ }^{2}$ Dalian V.R Global Vision Co., Ltd, Dalian 116025, P.R. China
}

\begin{abstract}
With rapid development of computer science, the means of the agricultural park planning are renewed continuously. Based on the long-term practice in the agricultural park planning, we put forward innovatively the integrated information processing technology in three dimensions in the paper, that is, information, time and spatial dimensions, On the basis of the coupling relation of multi-dimensional space, time and information, data information and time \& spatial elements in agricultural park planning can be integrated and utilized to the maximum by $3 \mathrm{D}$ VR calculation as a means of basic technology application; so that a park planning system which is integrating plane, space, time and information resources is formed. By this way, the method is available for the multi-level and fully informational agricultural park planning, and it is an approach to explore modern agricultural park planning in thinking and technical means.
\end{abstract}

Keywords: Omni-directional information processing technology, Agricultural park, Planning methods, VR technology.

\section{$1 \quad$ Introduction}

The region, a highly abstract and broad concept, is a regional space divided for the human's production and life [1]. There are different choices for an area type as the regional unit of regional planning for different research purposes and decision-making backgrounds [2][3]. Aiming at different planning areal units, some disciplines emerge, such as urban planology, which is involved in the comprehensive arrangement for future urban development, the rational urban layout and overall urban arrangement of

\footnotetext{
${ }^{*}$ Foundation Project. National Key Technology R\&D Program in the $12^{\text {th }}$ Five year Plan of China" study and demonstration on urban carbon sinks protection and improvement of key technical integration" (2011BAJ07B05).

** Maily engaged in Land-Use study.

**** Corresponding author: Institue of Agricultural Resources and Regional Planning, Chinese Academy of Agricultural Sciences, Doctor/Professor, Maily engaged in agriculture park planning and Agriculture resources management research.
} 
engineering construction [4]. In other words, the Urban Planology is a discipline dealing with urban and rural built environment by their land utilization and urban material spatial planning [5].

The idea of the balance urban and rural development is put forth in the Report of the Sixteenth CPC National Congress. So, many areas or parks are built successively nationwide such as agricultural sci-tech park, agricultural high and new tech area, agricultural sci-tech demonstration area, combined agricultural test area, high-tech agricultural park, agricultural demonstration area with high production and efficiency, and modern agricultural experiment park[6][7][8]. To sum up, all belong to modern agricultural area construction substantially, and are the important ways for development of modern agriculture [9][10][11]. Currently, there is no uniform evaluation standard and construction principle for planning and construction of numerous agricultural areas. Through a long-term practical study on planning and design of agricultural areas, we put forward the agricultural regional planology different from the urban planology and urban \& rural planning in research object and target. The agricultural regional planology deals with the agricultural park planning, construction and development with adjustment of agricultural structure and increase of farmers' income. This regional planology offers not only a method to realize modern agricultural regional planning by multilevel and full information, but also sustainable utility of agricultural resources and means of multi-dimensional technology. This will be a better approach for modern agricultural park planning in thinking and technology.

\section{Design Method of Park Planning System}

The traditional agricultural park planning is expressed in the form of the planning text and plane plan. With great increase of the planning and information contents, the single expression cannot well present the planning idea and contents, and introduction to new technical means becomes a new orientation of the park planning research. The routine park planning is available from time, space and information, but with integration of social economy and combination of space and time, we set forth the concept of the omni-directional processing technology to fit for new planning form, expression and contents. For the omni-directional processing technology, the coupling relation of the multi-dimensional space with time and information should be considered fully besides dependence of objects, scale effect, anisotropy of space and information layering linear in the multi-dimensionalal space. By calculating 3D VR technology as a basic application means, the data information and time \& spatial elements can be integrated and utilized in the park planning to the maximum so as to form a park planning system with plane, space, time and information resources.

The core of the omni-directional processing technology is the integration and application of information, time and spatial dimensions and resources, and the key to realize this processing is dependent on a tool system-the whole-park planning \& omni-directional VR processing system. By the special VR processing engine developed specially aiming at the park planning, the multi-dimensional space is built in the planning target area, and the information and time can be overlaid and integrated 
with the multi-dimensional space. With application of functional components, such omni-directional planning results as a scale result presented in the form of $3 \mathrm{D} V \mathrm{VR}$, planning scheme expressed by time and space, and automatically-generated maps and income from investment can be available. The omni-directional planning results include three major parts as shown in Fig. 1.

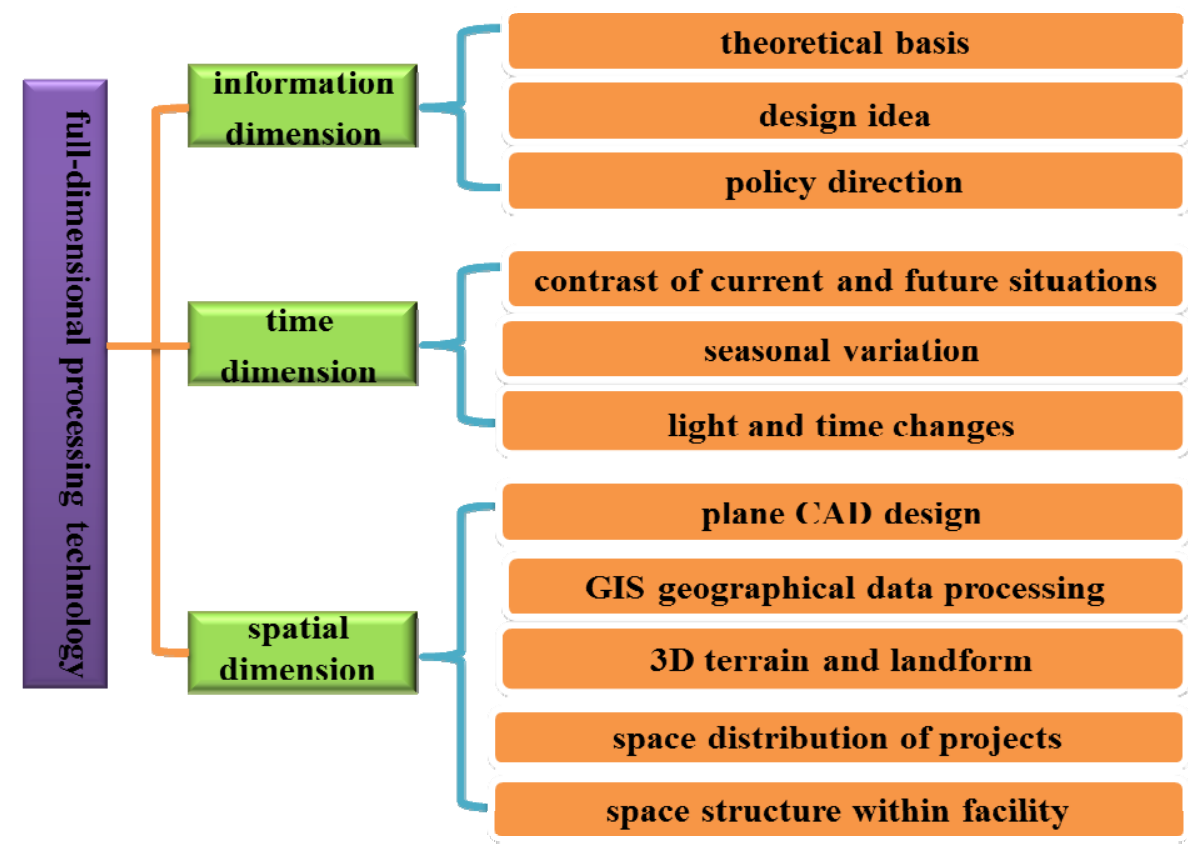

Fig. 1. Dimensional structure for omni-directional processing technology

\subsection{Information Dimension}

Information is a description of state and characteristics of objective things, and information itself is abstract and invisible with independency of carriers. Its transmission and effect of action are not limited to time and space. It is an independent dimension which can be beyond time and spatial dimensions defined in the physical conception.

With a long-term practical research on the agricultural park planning, it is believed that the information dimension involved in agricultural park planning refers to parts as follows:

(1) All kinds of agricultural information and data supporting the planning design in the process of agricultural park planning, including requirements and target of the region construction, land utilization, water conservancy and transport, agricultural resources, climate resources, social economy, etc.; 
(2) Design idea, design thought, national and local industrial policy, industrial standard, and calculating standard for income from the region investment formed during agricultural park planning design;

Above parts belong to key ones that the information dimension covers in the omni-directional conception, and all are important ideas and data foundations forming the agricultural park planning design results based on the omni-directional processing technology.

\subsection{Time Dimension}

Time, of objectivity and one dimension, is a parameter used to describe the occurring process of an event. It is an imaginary line of change and development of a thing. Both time and spatial dimensions consist of the space-time carrier of matter existence. The time dimension in agricultural park planning refers to parts as follows:

(1) The elements related to agricultural industry described in the process of agricultural park planning. They are reflected in development and change by time, including history, current situations and future planning of target regional agricultural industry at the macro-level; and include difference of characters in different time in different seasons, climates even a day for a specific planning project at the micro-level;

(2) The time dimension of agricultural park planning, which is overlapped with information and spatial dimensions based on omni-directional processing technology in the agricultural park planning processing, so that the designed results present the switching process of design scheme by time.

\subsection{Spatial Dimension}

Space is a form of matter existence relative to time. The space geographically includes the visual contents from the one-dimensional line, two-dimensional plane to three-dimensional body. Any thing has its distributional pattern, form and layout in space with interaction and mutual effect. It is found that the traditional multi-dimension from one dimension to three dimensions can't express and cover the planning information and idea completely. So, the spatial dimension aiming at agricultural park planning refers to the following parts:

(1) Such information as 3D terrain scenes, water infrastructure, electrical infrastructure, agricultural infrastructure, civil buildings, forests and fruit trees in the planning target region contained in agricultural park planning field;

(2) The visual expression for omni-directional agricultural park planning in the planning design. The visual expression is formed by structuring above multi-dimensional spatial information of the planning target region, with an overall application of CAD tool, GIS information, 3D modeling tool, database building and integrated information system. 


\section{Applications of the Omni-Directional Processing Technology in the Park Planning-An Example of Zhengding of Hebei Province}

\subsection{Background of Zhengding Modern Agricultural Park Planning for Hebei Province}

The main target for the Zhengding agricultural park planning construction is to recover and develop the geological environment of the Cihe Ancient Road Sandpit, where there are the typical criss-cross sandpits and ravines. In this case, the planning key and difficulty are how to carry out the planning of all kinds of projects in such a complicated terrain condition and how to design spatial layout and 3D levels rationally, so that the limited land and basic resources can be used sufficiently.

Supposing only the traditional planar technique is taken as the planning design method in the case, it is difficult to well express such time factors as seasonal variation and light change which impact the planning contents. For above said reasons, the omni-directional idea and method in this case can well be applied in the planning design. Meanwhile, by sufficiently making use of information, time and spatial elements obtained in study, the planning of the case can be well completed with the VR processing software which is developed independently by us.

\subsection{Technical Path of Omni-Directional Processing Technology Application}

In the park planning survey, it is very important to collect digital elevation terrain information, on-site live-action photos, positioning information, information of historical changes, and seasonal and climatic variation information about the planning area besides data acquisition and field survey and research. In implementation of the planning design, all kinds of information and data collected in the survey are put into the omni-directional VR processing system software which is developed independently by us, and the multi-dimensionalal spatial environment is built taking advantage of automatic processing unit analysis and processing digital elevation terrain data provided by the system. By this way, the 3D park planning design is realized. Major technical path is seen in Fig. 2.

\subsection{Technical Essentials for Omni-Directional Processing Technology Application}

In the realization of the case, major technical points are listed as follows:

(1) Work out the terrain maps of the planning area by the CAD application; realize the exhibition of 2D layout on the basis of the layout of agricultural regional planning;

(2) Collect types, distribution and scales of land use by GIS application and social economy data, to realize combination of spatial data and attribute data; 


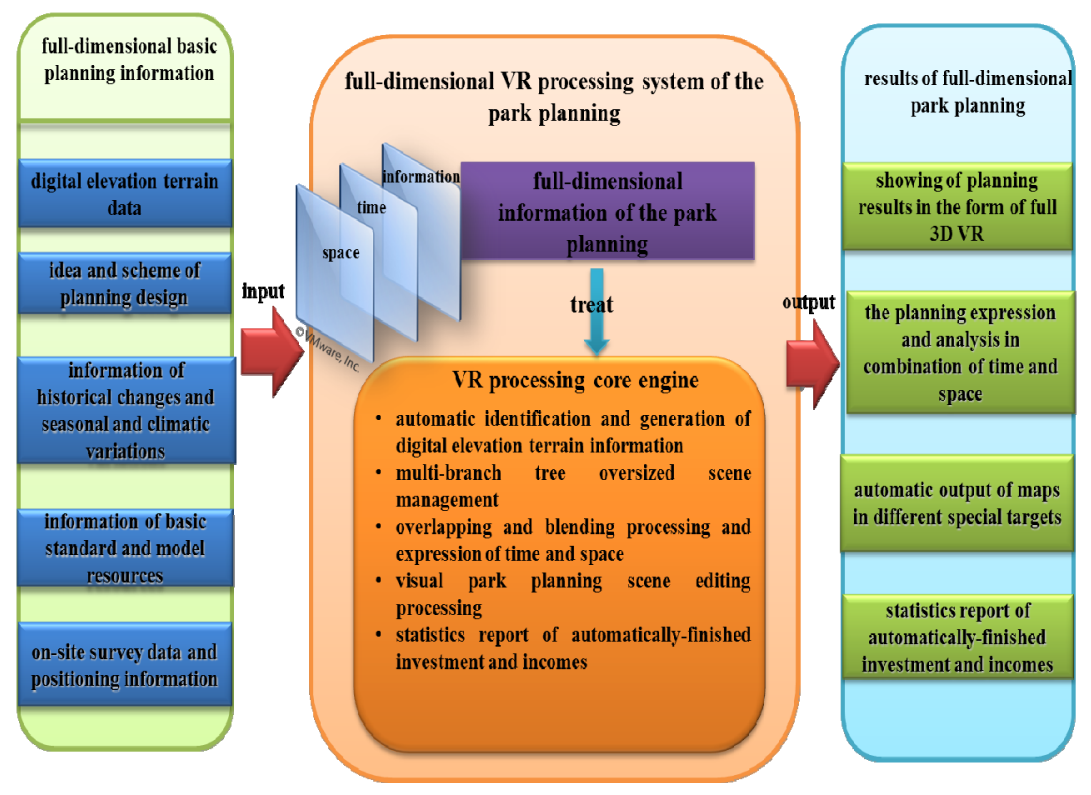

Fig. 2. Applied technology path of omni-directional processing technology for Zhengding Agricultural park planning in Hebei province

(3) Analyze digital elevation data and recover the terrains in the planning area through digital terrain processing units of the omni-directional system, so as to show the planning projects in valley economy and water-area ecological agriculture with complex spatial relation and layered distribution;

(4) Deal with a dynamic description of geographic advantages of the target area by a dynamic loading process of the supersized area scene of the system. Describe the abstract design conception directly about 3D agriculture, four-in-one ecological agriculture and channel scene transform in the planning target by making use of the system support to the 3D space expression;

(5) Realize the straight comparison of primitive state to the planning state in the target area, as well as direct exhibition of related influence on the planning projects in different seasons by overlapping process of space and time;

(6) Realize to complete the planning design based on omni-directional VR system software, as well as automatic uniform summarization output of the analytical data of planning investments and incomes.

All kinds of survey data, planning ideas and layout are integrated rationally with processing of above major key technical nodes. The major key technical nodes and system structure are shown in Fig. 3. 


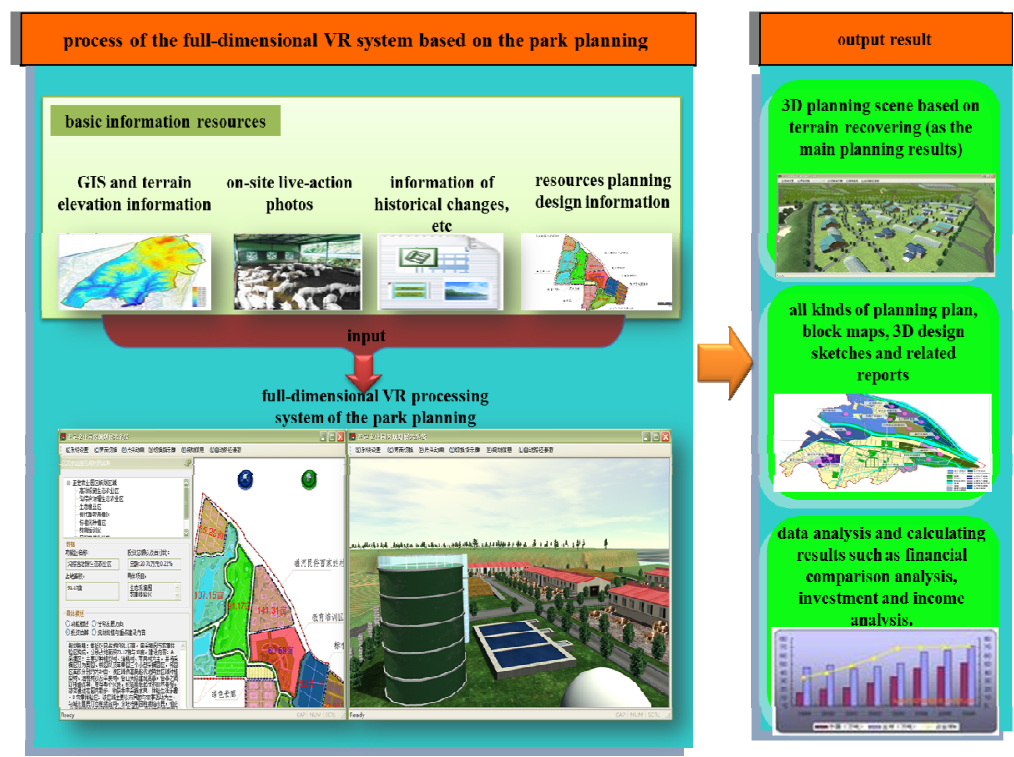

Fig. 3. Technical nodes and system structure of the omni-directional processing technology in Hebei Zhengding agricultural park planning

\section{Discussion and Conclusions}

The agricultural park planning based on omni-directional information processing technology should be further improved and developed in the following aspects through application and study on the combination of the traditional method and omni-directional processing technology of the agricultural park planning:

(1) The system graphic analyzing unit and module should be further improved. As the spatial and attribute data are put into the omni-directional VR processing system only by external software, for example, CAD and GIS's processing and information extraction, so this not only increases working load of data processing but also confines matching of file layout. Thus, improving the analyzing units and modules will reduce the working load of the data pre-processing and promote work efficiency;

(2) The social economy data processing and analytical system should be integrated. The social economy data in the planning area are the premise of the whole planning. The distribution and data analysis of the social economy in the planning area are the effective basis of the planning. Thus, the integration of the processing and analytical system of social economy data is an important supplement and perfection to the planning system;

(3) The coupling of units and modules in the system should be strengthened further. The omni-directional VR planning system is a new one which is a result of accumulation and research on the basis of the long-term agricultural park planning. The proposed analytical units and modules should be further adjusted and improved, and 
specially in coupling relation, it needs further studying to improve efficiency of data processing;

The agricultural park planning is a result on the basis of study on the layout of agricultural area and management of agricultural resources. It covers research results in theory as well as design results of agricultural engineering, and is a concentrated reflection of the small area and large-scale agriculture. Thus, it is very important to develop and improve technical means of the modern agricultural planning, and of importance for construction of the technical and standard system of the agricultural park planning.

\section{References}

1. Wang, H.: Theory and method of regional planning. Management World (2), 149-152 (1994)

2. Yan, Z., Zhou, K.: Thoughts on the regional planning of the cross-administrative areas. Economic Geography 15(14), 1-6 (1995)

3. Li, X., Wang, H.: The Analysis of the Trinity Planning of Eco-agricultural Tourism Park. Chinese Agricultural Science Bulletin 27(25), 300-306 (2011)

4. http://baike.baidu.com/view/1952434.html

5. http://baike.baidu.com/view/5422265.html

6. Guan, L.: Design and research of modern agricultural park planning-An example of Yangling modern agricultural demonstration area (Master dissertation). North West Agriculture and Forestry University, Shaanxi (2010)

7. Liu, S.: Study on the Plan and Design of Modern Agriculture Demonstration Garden. Journal of Anhui Agri. Sci. 39(35), 21875-21876 (2011)

8. Liang, F., Liu, L., Qu, Y.: Methodology of agricultural landscape classification with rural scale and its application in planning of new rural construction. Transactions of the CSAE 11(27), 330-335 (2011)

9. Zhao, H., Zhang, F.: Analysis of agricultural landscape and the zoning layout of agricultural function in Beijing. Transactions of the CSAE 24(supp.1), 78-84 (2008)

10. Li, X., Zhu, H.: Agro landscape changes and driving factors in coastal area of southeast Fujian: A case study of Dananban farm. Resources Science 22(1), 35-39 (2000)

11. Bian, Z., Wang, Q., Yu, M.: Empirical research on theory. Transactions of the CSAE 24(2), 95-100 (2008) 